\title{
RELAÇÃO ENTRE PODAS E ASPECTOS FITOSSANITÁRIOS EM ÁRVORES URBANAS NA CIDADE DE LUIZIANA, PARANÁ
}

\author{
Larissa Fernanda Vieira Martins ${ }^{1}$; Helisson Henrique Borsato de Andrade ${ }^{2}$; Bruno Luiz \\ Domingos De Angelis ${ }^{3}$
}

(recebido em 19.07.2010 e aceito para publicação em 15.12.2010)

\section{RESUMO}

A arborização urbana proporciona benefícios de ordem física, social e ecológica, desde que a árvore apresente-se saudável. Visto que o ambiente urbano não é propicio ao cultivo de árvores, faz-se necessária a adoção de práticas de manejo adequadas para assegurar a saúde da planta. O objetivo dessa pesquisa foi diagnosticar as práticas de podas efetuadas nas árvores viárias da cidade de Luiziana, Paraná, e a possível relação entre essa medida e os aspectos fitossanitários das árvores. Utilizou-se ficha de campo para levantar fatores in loco referente ao tipo de poda efetuada, ao ataque de pragas e à incidência de patógenos na planta. Analisaram-se 1540 árvores na área central da cidade. Constatou-se que a poda drástica é o tipo de poda mais utilizada e $72 \%$ das árvores apresentam-se aparentemente sadias. Cerca de $50 \%$ dos indivíduos que sofreram poda drástica apresentaram sinais de ataque por pragas e doenças, o que corrobora a relação entre poda e fitossanidade. $A$ espécie mais afetada pela poda drástica (Ligustrum lucidum) é também a espécie de maior predominância na população e com os maiores índices de ataque por patógenos e pragas.

Palavras-chave: poda drástica, pragas e doenças, fitossanidade.

\footnotetext{
1. Tecnóloga Ambiental, MSc. Doutoranda do Programa de Pós-Graduação em Geografia Física, Universidade de São Paulo - USP, São Paulo - SP. larissafvm@gmail.com

2. Tecnólogo em Gerenciamento Ambiental. Mestrando do Programa de Pós-Graduação em Engenharia Civil (Bolsista CAPES), Universidade Tecnológica Federal do Paraná - UTFPR, Curitiba - PR. helissonborsato@gmail.com

3. Eng. Agrônomo, Professor Doutor do departamento de Agronomia, Universidade Estadual de Maringá - UEM, Maringá - PR. brucagen@uol.com.br
} 


\section{THE RELATION BETWEEN PRUNING AND PHYTOSANITARY ASPECTS IN URBAN TREES IN THE TOWN OF LUIZIANA, PARANÁ STATE (BRASIL)}

\section{ABSTRACT}

The urban forestry brings benefits of physical, social, and ecological nature; for this, the trees need to be healthy. As the urban environment is not adequate to the cultivation of trees, there is a need to adopt appropriate management practices to ensure the health of the plants. The aim of this research was to diagnose the practices of pruning done in the street trees of the town of Luiziana, Parana State, and the possible relation between this procedure and the phytosanitary aspects of the trees. We used the field form to investigate factors in loco, such as the type of pruning carried out, if there were plague attacks, and any incidence of pathogens in the plants. We analyzed 1,540 trees in the downtown area. It was found that the drastic pruning is the most used kind and $72 \%$ of the trees are apparently healthy. About $50 \%$ of individuals which undergone drastic pruning present signs of plagues and diseases attack, a fact that confirms the relation between pruning and phytosanity. The species Ligustrum lucidum was the most affected by drastic pruning, and it is also the most prevalent tree species, as well as the species with the highest rates of pathogens and plagues attack.

Keywords: drastic pruning, plagues and diseases, phytosanity. 


\section{INTRODUÇÃO}

A arborização de vias públicas desempenha papel fundamental na qualidade ambiental urbana. A presença de vegetação nas cidades proporciona melhorias de ordem social e microclimática, minimiza a poluição hídrica, visual e sonora, além de propiciar condições para a manutenção da flora e fauna (MASCARÓ e MASCARÓ, 2002; GREY e DENEKE, 1978).

Para que as árvores cumpram com suas funções no ambiente urbano, mantendo-se em estado adequado e sadio, é necessária a adoção de práticas sistematizadas de manutenção, dentre as quais a poda, que deve ser conduzida por profissionais e norteada por conhecimentos técnico-científicos (MILANO e DALCIN, 2000).

Quando a poda é conduzida inadvertidamente, sem o uso de técnicas especificas, prejudica a planta, deixando-a exposta a agentes externos e desconfigurando sua arquitetura. A exposição do lenho permite a entrada de microorganismos e artrópodes que degradam a madeira e afetam negativamente sua fitossanidade. Os aspectos fitossanitários negativos mais notados em árvores urbanas são os ataques por pragas e doenças, responsáveis pela biodeterioração do vegetal. No Brasil, segundo Brazolin (2010), os cupins são responsáveis por grandes prejuízos à arborização urbana, não sendo rara a presença de ninhos nas árvores.

O objetivo dessa pesquisa foi diagnosticar os tipos de podas utilizados na arborização viária da cidade de Luiziana, Paraná, e correlacioná-las com potenciais aspectos fitossanitários negativos nas árvores urbanas que estejam vinculados à condução de maneira errônea dessa técnica.

\section{MATERIAL E MÉTODOS}

\section{Caracterização da área de estudo}

A cidade de Luiziana localiza-se na mesorregião geográfica Centro Ocidental do Estado do Paraná (IBGE, 2010a) e possui população de 7.540 habitantes, dos quais 4.138 vivem em área urbana (IBGE, 2010b).

De acordo com a classificação climática de Köppen a região apresenta clima tipo cfa - Clima subtropical (IAPAR, 2009). O município situa-se no vale Piquirivaí, entre as bacias

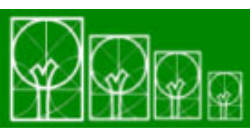

S · B · A : U Soc. Bras. de Arborização Urbana 
hidrográficas do Piquiri e do Ivaí (CAMPOS, 2005), com ocorrência natural de Floresta Estacional Semidecidual e de Floresta Ombrófila Mista Montana (IPARDES, 2010).

\section{Procedimentos técnico-operacionais}

Realizou-se levantamento da população arbórea na área central da cidade, totalizando 1540 árvores, com o intuito de identificar quais são as espécies associadas à incidência de pragas e/ou doenças. Para tal, utilizou-se uma ficha de campo, em que os critérios de análise foram adaptados de Silva Filho et al. (2002) e Bortoleto (2004), são eles:

a) Identificação: número de controle atribuído a cada árvore para controle dos dados, logradouro, espécie, gênero e família botânica.

b) Fitossanidade: sadia ou com doença e/ou praga. Todas as plantas em que se observou a presença direta de insetos ou indireta, através de excrementos, folhas cortadas ou serragem, foram assinaladas como contendo ataque por pragas como cupins, brocas de madeira e/ou formigas, não tendo por objetivo a identificação entomológica do organismo causador.

c) Intensidade do ataque: leve, quando sem dano ao vigor e à função da árvore; médio, quando há pequeno comprometimento ao seu vigor; e pesado, quando ocorreu alto grau de comprometimento ao vigor da planta;

d) Poda sofrida: sinais de poda visíveis no indivíduo arbóreo, classificando-se em: sem poda, poda drástica, poda em ' $V$ ', poda de contenção, poda de limpeza, poda de raiz e poda de formação.

As práticas de podas são conceituadas distintamente na literatura, ou seja, o mesmo tipo de poda recebe denominações diferentes. Para fins desta pesquisa foram adotadas as seguintes terminologias:

i) Poda de formação: consiste na eliminação dos ramos laterais ainda no crescimento da árvore, conferindo à copa uma altura adequada para o trânsito de pedestres e veículos (PIVETTA e SILVA FILHO, 2002);

ii) Poda de limpeza: consiste na retirada de galhos secos, mortos, doentes ou praguejados (PIVETTA e SILVA FILHO, 2002);

iii) Poda de contenção: visa adequar a copa da árvore ao espaço físico disponível em função de um plantio inadequado (PIVETTA e SILVA FILHO, 2002);

iv) Poda de emergência: visam remover partes da árvore que ameaçam a segurança da população, das edificações e instalações, como as redes aéreas. Deve ser 
realizada em situações de emergência. Comumente o efeito estético desta poda é desagradável. Posteriormente deve ser feita uma poda corretiva para manter 0 formato original ou, então, substituir por outra espécie mais adequada. A copa deve manter uma distância mínima de um metro da rede aérea, podendo ser feita em vários formatos: 'V', furo, 'L' e 'U' (PIVETTA e SILVA FILHO, 2002);

v) Poda drástica: caracteriza-se como poda drástica aquela que apresenta: (a) remoção total da copa, permanecendo acima do tronco apenas os ramos principais com menos de um metro de comprimento nas árvores adultas; b) remoção total de um ou mais ramos principais, resultando no desequilíbrio da árvore; c) remoção total da copa da árvore, restando apenas o tronco (CEMIG, 2006 apud MAREK, 2008);

vi) Poda de raiz: consiste na remoção ou corte de parte da raiz da planta, sendo realizada quando as mesmas obstruem passeio público, construções e tubulações (FÁTIMA, 2005).

Os dados brutos foram tabulados em planilhas do programa Microsoft Excel.

\section{RESULTADOS E DISCUSSÃO}

Cadastrou-se na área um total de 1540 árvores distribuídas em 47 espécies, 38 gêneros e 24 famílias botânicas. As espécies predominantes foram Ligustrum lucidum W. T. Aiton, Caesalpinia pluviosa DC., Schinus molle L., Murraya paniculata (L.) Jack, e Tibouchina granulosa (Desr.) Cogn.

Um total de $61 \%$ das árvores apresentou sinais visíveis de podas. Em Campos do Jordão (SP), Americana (SP) e Maringá (PR) foi constatado que 81,8; 52,6 e 84,5\% das árvores, respectivamente, apresentavam sinais de podas anteriores (ANDRADE, 2002; SILVA, 2005; SAMPAIO, 2006). Assim como nesses locais, em Luiziana a poda é prática corriqueira, realizada com o objetivo de comportar a árvore ao espaço físico disponível.

O tipo de poda mais empregado em Luiziana foi poda drástica, com 20,8\% do total de casos observados, seguido pelas podas de condução $(15,4 \%$,) e de formação $(11,4 \%)$ (Tabela 1).

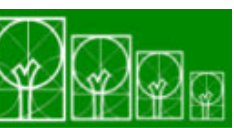

$\mathbf{S} \cdot \mathbf{B} \cdot \mathbf{A} \cdot \mathbf{U}$ Soc. Bras. de Arborização Urbana 
TABELA 1 - Tipo de poda empregado na arborização urbana na cidade de Luiziana, total de árvores e frequência relativa (\%).

TABLE 1 - Type of pruning used in urban forest in the town of Luiziana, total number of trees, and relative frequency (\%).

\begin{tabular}{lcc}
\hline Tipo de Poda & Total & Frequência (\%) \\
\hline Sem Poda & 596 & 38,7 \\
Poda Drástica & 321 & 20,8 \\
Poda de Contenção & 237 & 15,4 \\
Poda de Formação & 176 & 11,4 \\
Poda de Contenção e Drástica & 85 & 5,5 \\
Poda de Limpeza & 49 & 3,2 \\
Poda em 'V' & 21 & 1,4 \\
Poda de Contenção e Poda em 'V' & 17 & 1,1 \\
Poda de Limpeza e Contenção & 13 & 0,8 \\
Poda de Raiz e Drástica & 7 & 0,5 \\
Poda de Raiz e Contenção & 6 & 0,4 \\
Poda de Limpeza e Drástica & 5 & 0,3 \\
Poda de Raiz, Contenção e 'V' & 3 & 0,2 \\
Poda de Raiz & 2 & 0,1 \\
Poda Drástica e 'V' & 1 & 0,1 \\
Poda de Limpeza, Contenção e 'V' & 1 & 0,1 \\
\hline Total & $\mathbf{1 5 4 0}$ & $\mathbf{1 0 0}$ \\
\hline
\end{tabular}

Em Maringá, as podas drásticas representam 0,96\%, das práticas empregadas nas árvores urbanas (SAMPAIO, 2006), comparado a esta localidade, Luiziana apresenta um excessivo emprego desta técnica.

As podas mais severas, tais como as podas drásticas, favorecem posteriormente 0 aparecimento das brotações epicórmicas. A poda provoca um desequilibro entre folhas e raízes ocasionando uma reação compensatória no vegetal (MILANO e DALCIN, 2000). Essa reação manifesta-se através da quebra de dormências das gemas epicórmicas, gerando brotações que levam a um aumento do número de podas, pois a ausência do controle das brotações gera em pouco tempo novos galhos a serem podados novamente (MILANO e DALCIN, 2000). Estes novos galhos são frágeis e suscetíveis a quedas devido a ações intempéricas. Fátima (2005) salienta que a realização da poda drástica pode fazer com que 
os ramos epicórmicos atinjam as eventuais fiações elétricas próximas mais rapidamente.

Dentre as espécies que sofreram poda drástica, L. lucidum foi à espécie mais afetada, com 67,3\% dos casos, seguida por T. granulosa (8,4\%), C. pluviosa $(7,5 \%)$, e $S$. molle $(6,9 \%)$. A soma de todas as outras espécies que sofreram poda drástica representa $10 \%$ do total.

Verifica-se que dentre as árvores em que foi realizada poda drástica (Figura 1), um total de $41,12 \%$ de árvores não se encontravam sob a rede elétrica (Figura 2), fator que corrobora para a premissa de que este tipo de técnica vem sendo empregada de maneira errônea na cidade. Esta prática deve ser substituída gradativamente, principalmente nos novos indivíduos presentes na arborização, uma vez que consiste em uma medida supressora e deve ser utilizada somente em casos de extrema necessidade, por agredir a integridade da planta, deixando-a exposta a agentes externos, além de desconfigurar a árvore arquitetonicamente ocasionando a redução ou perda dos benefícios estéticos do vegetal.

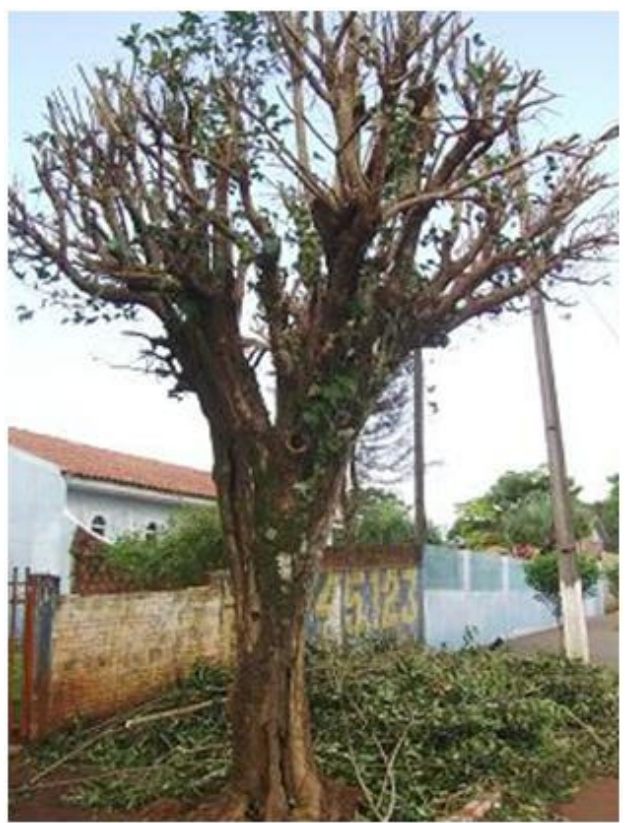

(a)

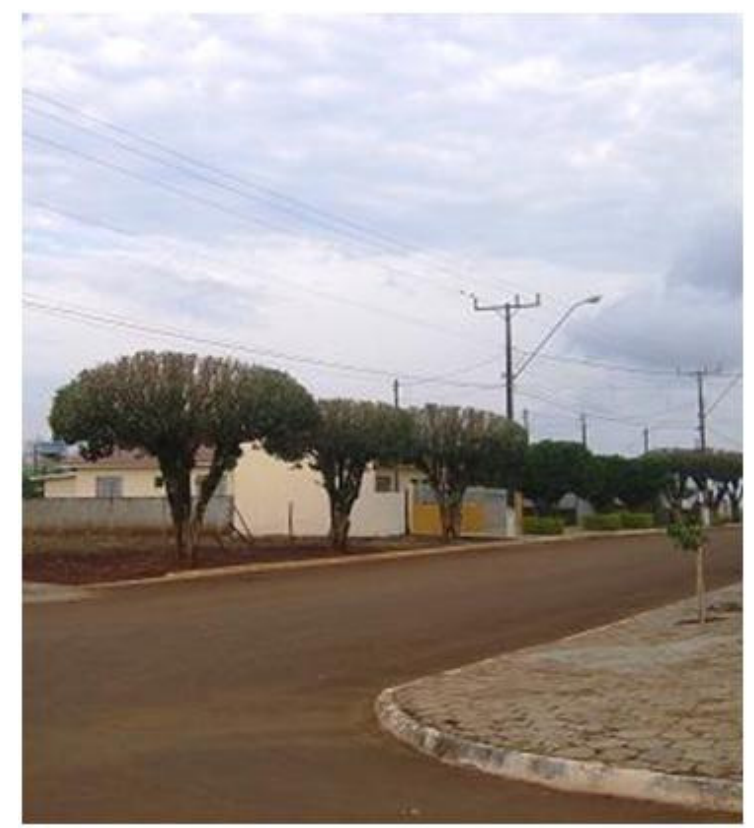

(b)

FIGURA 1 - Ligustrum lucidum nas vias públicas de Luiziana: (a) indivíduo recém-podado drasticamente, (b) composição de L. lucidum afetados pelas podas drásticas.

FIGURE 1 - Ligustrum lucidum in the streets of Luiziana: (a) individual newly drastically pruned, (b) composition of $L$. lucidum affected by drastic pruning. 


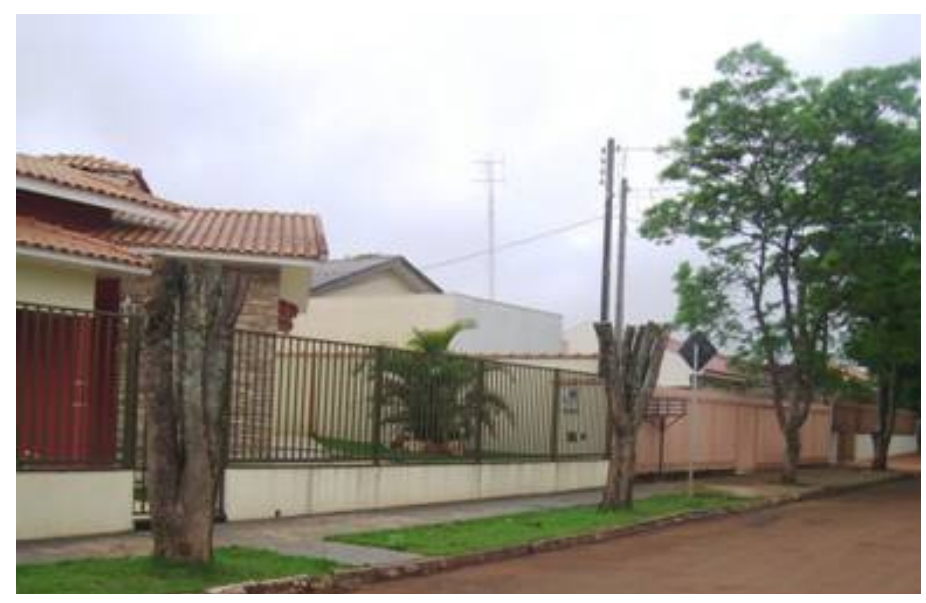

FIGURA 2 - Vista parcial de Caesalpinia pluviosa podada drasticamente em área sem fiação elétrica em Luiziana.

FIGURE 2 - Partial view of Caesalpinia pluviosa drastically pruned in an area without electric light wiring in Luiziana.

\section{Aspectos fitossanitários}

Os sintomas identificados como sinais do ataque de doenças foram murchamento, manchas claras e lesões necróticas. Quanto às pragas identificaram-se sinais de cupins, formigas e brocas de madeira.

Verificou-se que $72 \%$ das árvores avaliadas não apresentam sinais aparentes do ataque por pragas e doenças, $13 \%$ apresentaram sinais de ataques por pragas, $7 \%$ com sinais de incidência de doenças e $8 \%$ apresentaram sinais de ataques por pragas e doenças simultaneamente, ou seja, $28 \%$ das árvores evidenciaram sinais de pragas e/ou doenças.

Em Americana (SP), Silva (2005), relatou sinais da presença de pragas em 11,9\% da população trabalhada e sinais de doenças em 9,13\%. Bortoleto (2004) verificou em Águas de São Pedro (SP) sinais de ataques de pragas em $0,57 \%$ da população trabalhada. Andrade (2002) não fez uma segregação distinta entre pragas e doenças na arborização viária de Campos do Jordão (SP), entretanto relata que $1,8 \%$ da população arbórea apresentaram sinais de incidência desses fatores.

Comparativamente com as áreas supracitadas, Luiziana apresentou altos percentuais de aparentes sinais do ataques por pragas e doenças, fato que pode estar vinculado à alta incidência de podas drásticas e às elevadas proporções de indivíduos de mesma espécie, fator que favorece a proliferação de organismos indesejáveis. 
Segundo Santamour Júnior (1990), a diversidade de espécies na arborização urbana é necessária para evitar a propagação de pragas e doenças nas árvores presentes neste ambiente entre indivíduos de mesma espécie.

\section{a) Doenças}

A população arbórea com sinais de ataque por fungos totalizou 106 indivíduos em 1540 plantas. Os indivíduos com sinais de ataques somente por fungos consistiram em apenas cinco espécies: L. lucidum, C. pluviosa, S. molle, T. granulosa e Eriobotrya japonica (Thunb.) Lindl. Dentre o ataque por doenças destacou-se o cancro de tronco (Figura 3). A espécie L. lucidum representou $50 \%$ da incidência de doenças, seguida por $C$. pluviosa $(40,6 \%)$, S. molle (5,7\%), T. granulosa (2,8\%) e E. japonica (menos de $1 \%)$. Ressalta-se que a maior incidência de ataques em $L$. lucidum se deu devido à sua predominância em relação às demais espécies e a alta incidência da técnica constante de podas drásticas.

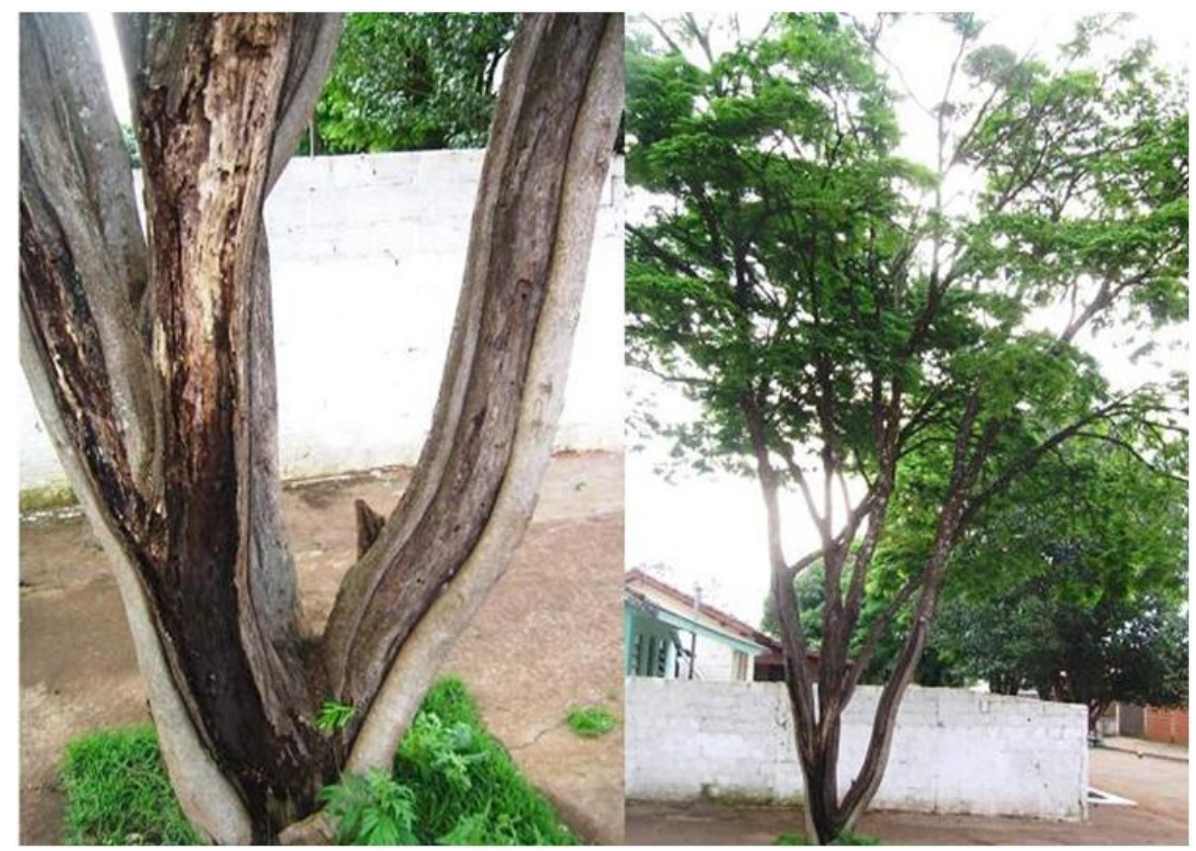

Figura 3 - Vista parcial da incidência de cancro do tronco e praga em Caesalpinia pluviosa na Avenida Independência em Luiziana.

Figure 3 - Partial view of the incidence of trunk canker and plague in Caesalpinia pluviosa on Independence Avenue in Luiziana.

Segundo De Angelis et al (2007), o cancro do tronco é um dos problemas mais notáveis na arborização de Maringá. A doença ataca árvores de todas as idades, onde o 
processo de necrose mais avançado é comumente observado em árvores antigas. A doença inicia-se pela entrada do patógeno por algum ferimento, via de regra ocasionado pelo homem, podendo ser resultante de poda, desbrota, ou então danos causados por insetos, brocas, entre outros.

\section{b) Pragas}

Foram observados ataques de pragas em 197 das 1540 plantas avaliadas. A espécie mais atacada foi $L$. Iucidum que representou $40 \%$ do total de ataques observados, seguido por C. pluviosa (30,5\%), T. granulosa (13,2\%), S. molle (5,6\%), Cassia fistula L. $(2,5 \%)$, Delonix regia (Bojer ex Hook.) Raf. (1\%). As demais espécies (Mangifera indica L., E. japonica, Hibiscus rosa-sinensis L., Leucaena leucocephala (Lam.) de Wit. e Prunus persica (L.) Batsch) representaram $0,5 \%$ dos ataques por pragas.

Novamente L. lucidum aparece como a espécie com maior aspecto fitossanitário negativo, uma vez que a espécie consiste na árvore mais plantada na cidade $(24,65 \%$ do total da população arbórea), corresponde aos plantios mais antigos e consequentemente tem sido a árvore em que mais se observa a prática de poda drástica.

\section{c) Pragas e doenças}

Houve 134 árvores de cinco espécies com incidência combinada de fungos e pragas: L. Iucidum (63\%), C. pluviosa (22,4\%), S. molle (6,7\%), T. granulosa $(4,5 \%)$ e Caesalpinia ferrea var. leiostachya Benth. (3\%).

Verificou-se que a destruição da madeira ocasionada por pragas comumente foi precedida pelo ataque de fungos, visto que as condições necessárias para a ocorrência de ambos sejam semelhantes (KOFOID et al., 1934 apud AMARAL, 2002).

Dentre as árvores atacadas por doenças, pragas ou ambas, quatro espécies estão presentes nos três grupos: L. Iucidum, C. pluviosa, T. granulosa e S. molle. A espécie em que se verificou maiores percentuais de ínvidos sadios foi $S$. molle, em contrapartida $L$. lucidum possui os maiores valores de indivíduos com sinais de ataques por doenças e pragas (Figura 4 e 5). 


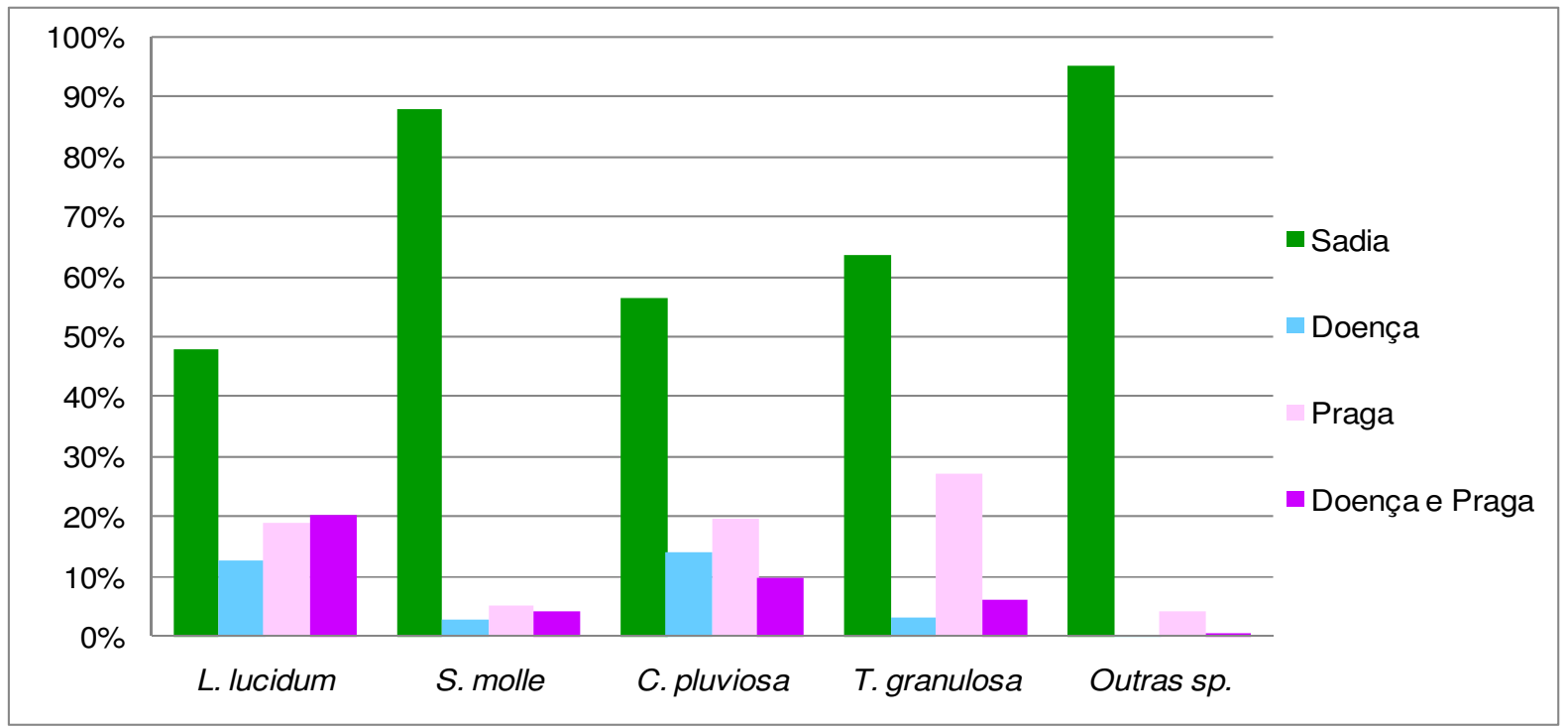

FIGURA 4 - Fitossanidade na população de: Ligustrum lucidum, Schinus molle, Caesalpinia pluviosa, e Tibouchina granulosa presentes no acompanhamento viário da Cidade de Luiziana.

FIGURE 4 - Phytosanity in the population of: Ligustrum lucidum, Schinus molle, Caesalpinia pluviosa, and Tibouchina granulosa observed on the streets monitoring in the town of Luiziana.
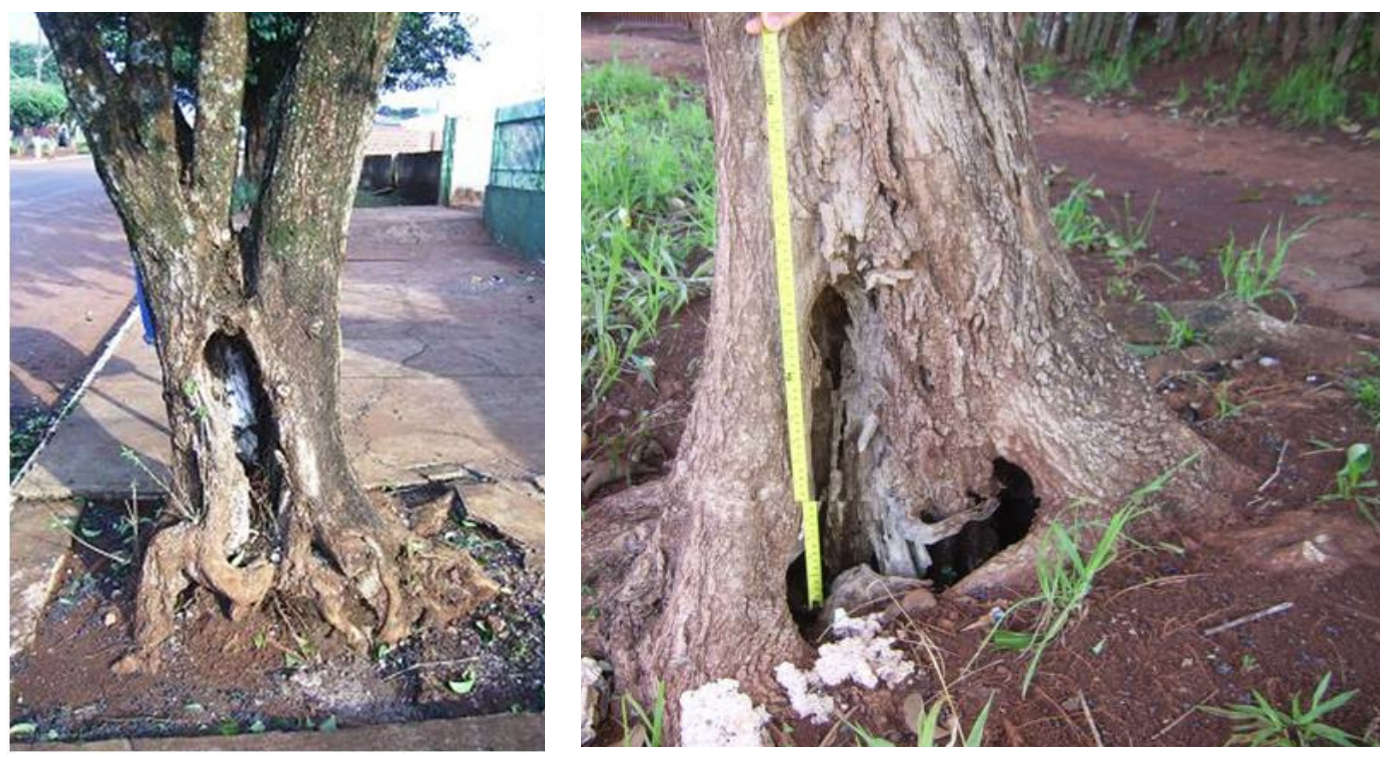

FIGURA 5 - Vista parcial de danos ocasionados a indivíduos de Ligustrum lucidum pela incidência de pragas e doença na Avenida Liberdade em Luiziana.

FIGURE 5 - Partial view of damage caused to individuals of Ligustrum lucidum by the incidence of plagues and diseases on Liberdade Avenue in Luiziana.

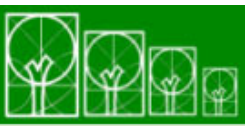

$\mathbf{S} \cdot \mathbf{B} \cdot \mathbf{A} \cdot \mathbf{U}$ Soc. Bras. de Arborização Urbana

REVSBAU, Piracicaba - SP, v.5, n.4, p.141-155, 2010 


\section{Severidade dos danos}

A intensidade dos danos ocasionados por pragas e doenças, foi classificada de acordo com a metodologia descrita por Bortoleto (2004) em leve, médio, e pesado. Verificou-se que $87,7 \%$ das árvores que apresentaram vestígios do ataque por doenças encontram-se com o grau leve, 11,3\% médio e apenas 0,94\% pesado. Quanto ao dano ocasionado por pragas $73,4 \%$ é considerado leve, $18,8 \%$ médio, e $0,78 \%$ pesado. $\mathrm{Na}$ combinação doença e praga $42,7 \%$ foram classificados como médio, seguidos por $31,6 \%$ leve, e $25,7 \%$ pesado.

\section{Poda versus fitossanidade}

Diante da avaliação dos dados obtidos pode-se estabelecer relação entre indivíduos que sofreram podas mais severas com os aspectos fitossanitários negativos. As árvores com maiores percentuais de "sadias" comumente não apresentaram nenhum tipo de poda ou foram submetidas a podas pouco impactantes como poda de formação e poda de limpeza, os maiores percentuais de árvores com aspectos fitossanitários negativos foram evidenciados em árvores que sofreram ações mais severas, como poda drástica, poda de raiz ou a ação combinada de diferentes tipos de podas, ou seja, as árvores que sofreram maiores números de intervenções (Figura 6). 


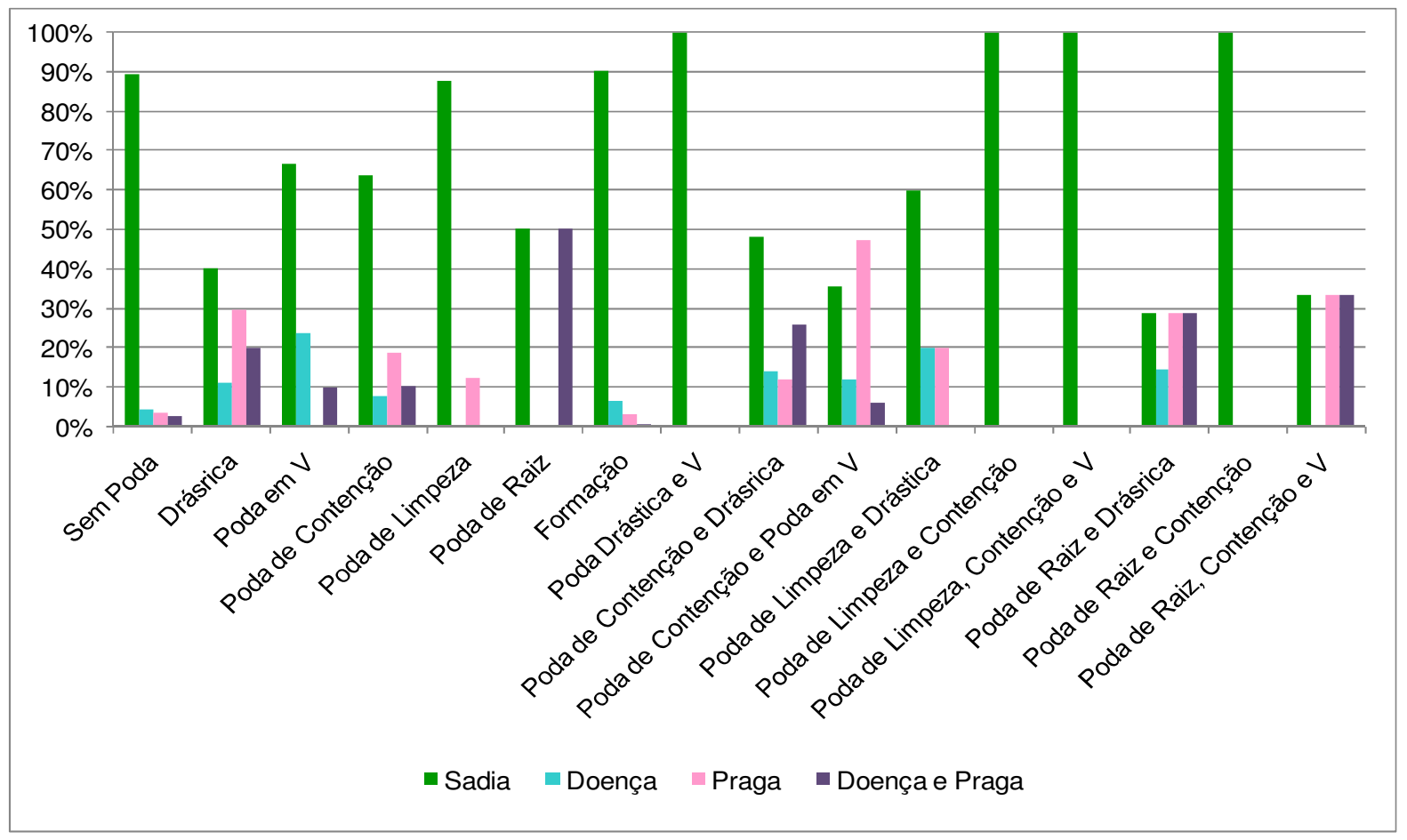

FIGURA 6 - Relação existente entre o tipo de poda sofrida e aspectos fitossanitários nas plantas presentes no acompanhamento viário da Cidade de Luiziana, Paraná.

FIGURE 6 - Relation between the type of pruning and plant phytosanitary aspects observed on the streets monitoring in the town of Luiziana.

As podas severas ocasionam injúrias nas árvores, principalmente a poda drástica, que é comumente utilizada na cidade. Comumente evidencia-se ataques por insetos primeiramente em galhos e ramos que sofrem injúrias mecânicas, como a poda drástica. Faz-se necessário que esta prática seja reduzida gradativamente na área, tendo em vista a forte relação existente entre a prática e a saúde da planta.

\section{CONCLUSÕES}

A espécie de maior predominância na população arbórea é Ligustrum lucidum, também é a espécie que mais sofreu poda drástica e mais atacada por pragas e doenças. Das quarenta e sete espécies avaliadas, treze apresentaram sinais de pragas e/ou doenças.

É necessário escolher a árvore certa para o espaço certo com o intuito de se evitar eventuais transtornos ocasionados pela incompatibilidade do vegetal para com a área, reduzindo assim, o número de podas praticadas e consequentemente contribuindo para uma melhor saúde do vegetal.

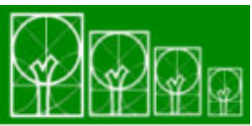

S $\cdot \mathbf{B} \cdot \mathbf{A} \cdot \mathbf{U}$ Soc. Bras. de Arborização Urbana 


\section{REFERÊNCIAS BIBLIOGRÁFICAS}

AMARAL, R. D. A. M. Diagnóstico da ocorrência de cupins xilófagos em árvores urbanas do bairro de Higienópolis, na Cidade de São Paulo. 2002. 84p. Dissertação (Dissertação em Recursos Florestais) - Escola Superior de Agricultura "Luiz de Queiroz". Universidade de São Paulo. Piracicaba, 2002.

ANDRADE, T. O. Inventário e análise da arborização viária da estância turística de Campos do Jordão, SP. 2002. 128p. Dissertação (Mestrado em Agronomia) - Escola Superior de Agricultura “Luiz de Queiroz". Universidade de São Paulo, Piracicaba, 2002.

BORTOLETO, S. Inventário quali-quantitativo da arborização viária da Estância de Águas de São Pedro. Piracicaba, 2004. 99p. Dissertação (Mestrado em Agronomia) Escola Superior de Agricultura "Luiz de Queiroz. Universidade de São Paulo, 2004.

BRAZOLIN, S. Biodeterioração e biomecânica das árvores urbanas (Palestra). Disponível em: <http://www.sbau.org.br/sbau/Sergio_Brazolin.pdf> Acesso em: 14 maio 2010.

CAMPOS, J. B. (coord.). Plano de Manejo do Parque Estadual Lago Azul. Curitiba: IAP/DIBAP, 2005. 35/IIp.

DE ANGELIS, B. L. D.; CASTRO, R. M.; DE ANGELIS NETO, G. Ocorrência do cancro de tronco em árvores de acompanhamento viário na cidade de Maringá, Paraná. SBAU. Piracicaba, v. 2, n.2, p. 31-45, 2007.

FÁTIMA, M. Estudo dos impactos ambientais da interação da rede de distribuição de energia elétrica com a arborização urbana nos municípios da região metropolitana do Recife. 2005. 173p. Dissertação (Mestrado em Gestão e Políticas Ambientais) Universidade Federal de Pernambuco. Recife, 2005.

GREY, G. W.; DENEKE, F. J. Urban Forestry. New York: John Wiley, 1978. 279p

IAPAR (Instituto Agronômico do Paraná). Cartas Climáticas do Paraná. Disponível em: <http://www.iapar.br/modules/conteudo/conteudo.php?conteudo=863> Acesso em: 13 ago. 2009.

IBGE. Território. Disponível em:

$<$ http://www.sidra.ibge.gov.br/bda/territorio/infounit.asp?codunit=5231\&codunitibge $=4113$ 734\&nomeunit=Luiziana+\%2D+PR\&n=6\&nomenivel=Munic\%EDpio\&z=t\&o=4>Acesso em: 20 jan. 2010a

IBGE. População. Disponível em:

<http://www.ibge.gov.br/home/estatistica/populacao/censo2000/universo.php?tipo=31o/ta 
bela13_1.shtm\&paginaatual=1\&uf=41\&letra=L> Acesso em: 20 jan. 2010b.

IPARDES. Cobertura vegetal original do estado do Paraná. Disponível em: <http://www.ipardes.gov.br/modules/conteudo/conteudo.php?conteudo=134> Acesso em: 10 fev. 2010.

MAREK, C. F. Os impactos da arborização viária sobre a rede de distribuição de energia elétrica: estudo de caso da Zona 7 de Maringá/PR. 2008. 89p. Dissertação (Mestrado em Engenharia Urbana) - Universidade Estadual de Maringá. Maringá, 2008.

MASCARÓ, L. R.; MASCARÓ, J. L. Vegetação Urbana. Porto Alegre: UFRGS, 2002. 242p.

MILANO, M.; DALCIN, E. Arborização de vias públicas. Rio de Janeiro: Light, 2000. 206p.

PIVETTA, K. F. L.; SILVA FILHO, D. F. Arborização Urbana. Boletim Acadêmico. Jaboticabal: UNESP/FCAV/FUNEP, 2002. 74p.

SAMPAIO, A. C. F. Análise da arborização de vias públicas da área piloto de Maringá. 2006. 116p. Dissertação (Mestrado em Geografia) - Universidade Estadual de Maringá, Maringá, 2006.

SANTAMOUR JÚNIOR, F.S. Trees for urban planting: diversity uniformity, and common sense. In: Metria Conference, 7. 1990, Proceedings. Lisle: p.57-66, 1990.

SILVA FILHO, D. F.; PIVETTA, P. V. C.; ALMEIDA, J. B. S. A.; PIVETTA, K. F. L.; FERRAUDO, A. S. Banco de dados relacional para cadastro, avaliação e manejo da arborização urbana. Rev. Árvore. Viçosa, v.26, n.5, p.629-642, 2002.

SILVA, L. F. Situação da arborização viária e proposta de espécies para os bairros Antônio Zanaga I e II, da cidade de Americana-SP. 2005. 80p. Dissertação (Mestrado em Agronomia) - Escola Superior de Agricultura "Luiz de Queiroz". Universidade de São Paulo. Piracicaba, 2005. 